\title{
Chapter 3 \\ Towards Integration of Modelling in Secondary Mathematics Teaching
}

\author{
Morten Blomhøj
}

\begin{abstract}
The inclusion of models and modelling in mathematics curricula has been a major trend internationally in recent decades. This has taken place in interplay with research on the teaching and learning of modelling and applications. However, it is still a pending challenge for research how to support real integration of modelling and applications into mathematics teaching. At the secondary school level in particular, the duality between the aim of developing students' modelling competence and that of supporting their learning of mathematics through modelling activities is essential for understanding and furthering the integration. The interplay between research and the development of teaching practices with regard to these two aims is discussed. In particular, the potential and challenges of using theories on the learning of mathematics to support the integration of modelling as a didactical approach will be illustrated and discussed in relation to two examples of mathematical modelling of dynamical phenomena at secondary level.
\end{abstract}

Keywords Secondary mathematics $\cdot$ Integration of modelling $\cdot$ Modelling competence $\cdot$ Conceptual learning $\cdot$ Modelling dynamical phenomena

\subsection{Introduction}

Research on the teaching and learning of mathematical modelling has developed to a level where it constitutes its own field of research within the mathematics education community (see Niss et al. 2007, pp. 28-32). Through this research, a coherent theory consisting of four main elements has been established: (1) A set of potential and actually used justifications for including modelling and application at different levels; (2) Conceptions of a mathematical model, a modelling process and of modelling competence, and related well-argued for and empirically tested ways of supporting the students' development of modelling competency and their learning

\author{
M. Blomhøj ( $\varangle)$ \\ Roskilde University, DES, bygn. 27, Universitetsvej 1, 4000 Roskilde, Denmark \\ e-mail: Blomhoej@ruc.dk


of mathematics through modelling activities; (3) Experiences and theoretical based knowledge about opportunities and challenges in teaching, learning and assessing of modelling competency; and (4) Theoretical based methodologies for developing teaching practices through (in-service) education and collaboration between teachers and researchers in developmental projects.

In his plenary address at ICME-12, Werner Blum surveyed the achievements in the field from the perspective of what it tells us about quality in the teaching of applications and modelling at secondary level. Based on empirical findings, Blum identified ten important aspects in a teaching methodology integrating modelling and applications (Blum 2015, pp. 83-86). However, he concluded with the following remark:

I would like to emphasise that all these efforts will not be sufficient to assign applications and modelling its proper place in curricula and classrooms and to ensure effective and sustainable learning. The implementation of applications and modelling has to take place systemically, with all system components collaborating closely: curricula, standards, instruction, assessment and evaluation, and teacher education. (p. 87)

One important contribution from research to such a systemic approach is to develop further the interplay with teaching practices. This challenge, however, stands differently with regard to the two ends of the dual aim for integrating applications and modelling in secondary mathematics teaching; namely to support the students' development of modelling competence or to enhance the students' learning of mathematics by means of modelling and applications. Therefore, for analytical purposes, in this chapter a distinction is made between these two aims, although they are closely connected in a duality.

With regard to the first aim, the research has developed in interplay with the practices of teaching modelling in specific courses of lessons or as part of developmental projects. The research surveyed by Blum (2015) provides a strong basis for a teaching practice aiming at developing the student's modelling competence. In Maaß (2006) the concept of modelling competence is unfolded with respect to the modelling cycle and related reflections. In Blomhøj and Højgaard (2007) modelling competency is discussed as a main justification for secondary mathematics in general education. Working with the entire process of mathematical modelling - the full modelling cycle-is here seen as the natural and necessary constituent of the development of modelling competency in teaching (pp. 48-49). Research has pinpointed theoretically and empirically learning difficulties related to the different phases in the modelling process, see for example Borromeo Ferri (2006). Moreover, research has developed different ways of conceptualising progress in the (individual) students' modelling competency. Blomhøj and Højgaard (2007) described progress in modelling competency using the notions from the Danish KOM-project (Niss and Højgaard 2011) and wrote about the development of modelling competency in three dimensions, namely the degree of coverage with respect to the modelling cycle, the technical level-mathematically and/or in modelling techniques, and the domain of action-meaning the domain of extra-mathematical situations in which the modelling competency can be put into action. Other researchers define different levels 
of modelling competency by means of the students' understanding of, and reflection on, their modelling work, see for examples vom Hofe et al. (2005). Kaiser and Brand (2015) analyse how the concept of mathematical modelling competencies has developed in research during the latest three decades. With regard to the aim of developing students' modelling competencies, it is still a challenge for research to establish a basis for conceptualising students' progress in and level of competency in modelling.

However, in general, research on the teaching and learning of modelling provides theory based designs for, and investigations of, many different ways of organizing mathematical modelling activities in classrooms with the aim of developing the students' modelling competencies. A rich and extensive documentation thereof is found in the International Community of Teachers of Mathematical Modelling and Applications (ICTMA) biennial international conferences and in the related volumes in the Springer book series International perspectives on the teaching and learning of mathematical modelling, see http://www.ictma.net/.

The theories developed are to a high degree aligned with the development of practices of teaching modelling with the aim of developing the students' modelling competencies. The basic concepts, notions and theories about models and modelling are developed in close interplay with the development of teaching practices, and are therefore, in principle, quite easily applied in designing and/or analysing mathematical modelling activities in classrooms.

With regard to the second main aim of teaching mathematical modelling at secondary level, namely to support the students' learning of mathematics the situation is different. The theoretical foundations for the potential of using modelling as a didactical vehicle for supporting the students' learning of mathematical concepts and methods are to be found not only in research on the learning of applications and modelling, but also in research on the learning of mathematics in general. In the field of research on the teaching and learning of modelling there are three frameworks, which have a particular focus on modelling as a means for supporting the students' learning of mathematics. Two of them can be characterized as having an epistemological perspective on modelling, namely Realistic Mathematics Education (RME) and The Anthropological Theory of Didactics (ATD). These are both comprehensive frameworks covering mathematics teaching and learning in general. The third framework is the Models and Modelling Perspective (MMP) and can be characterized as having a contextual problem solving perspective on modelling (Kaiser and Sriraman 2006).

In RME and ATD, modelling is subordinated amongst more general theories on the teaching and learning of mathematics. In RME the learning process is understood as the learners' dynamical reinvention of mathematical knowledge through the process of mathematisation (Freudenthal 1983). The process starts with students' mathematising their experienced reality in different contexts (horizontal mathematisation). Thereby, the students develop a foundation for acquiring the theoretical meaning of the concepts and methods used. This learning process is conceptualized in RME as vertical mathematisation. Through mathematizing with an increasing level of abstraction the mathematical concepts gradually obtain their theoretical meaning. The notion 'from model of [some particular type of situation] to model for [under- 
standing a mathematical concept]' is essential in RME for understanding the changing role of models in the process of learning mathematical concepts (Gravemeijer and Doorman 1999).

ATD offers a general and strong theory for understanding and designing mathematics teaching. The basic assumption is that mathematical knowledge - and human knowledge in general-is developed with the aim of contributing to the answering of some specific type of questions, and that mathematics teaching therefore should identify and use as its point of departure for teaching such generating questions for the mathematical knowledge in the curricula. The didactical research under ATD therefore develops and investigates implementations of what is called Activity of Study and Research organized around a question with strong generative power (Chevallard 2011). To the degree that the questions are referring to extra-mathematical situations and contexts - and that is typically the case - the ATD approach places mathematical modelling in the centre of the learning of mathematics emphasizing modelling as a didactical means for learning mathematics rather than modelling competency as an aim.

Within MMP, the research often focuses on what it means to understand particular important mathematical concepts and methods in different situations and contexts, and on how to design modelling activities where the students can activate the pinpointed aspects of the concepts in their modelling activities (Doerr and Lesh 2011). These didactical activities are called Modelling Eliciting Activities (MEA), and a set of design principles for MEAs has been developed and tested in many projects (e.g., Lesh and Doerr 2003). Points of departure are taken in everyday real-life contexts, in meaningful contexts established in the teaching, or in authentic applications in other disciplines or professions. Emphasis is placed on the students' construction of meaningfulness in the modelling process and through related reflections in the support of the students' learning of mathematics. However, research within MMP is also concerned with developing the students' competencies in problem solving and mathematical modelling. Both ATD and MMP take a systemic approach and include the interplay between the activities in class, the teachers' activities before, under and after the teaching, the researchers' activities and the interaction between the teachers and the researchers.

As a common core, all three frameworks build on the assumption that the learning potentials of modelling lie in the fact that the students' learning of mathematical concepts can be anchored and given cognitive roots through the students' modelling activities. The students' conceptual understanding can be challenged and developed further through working with modelling and applications in a variation of contexts.

Research has long since identified, investigated empirically, and explained theoretically learning difficulties principally related to the learning of mathematical concepts. These theories are developed independent of the frameworks for modellingbased teaching described above. However, as illustrated in the sections to follow, these theories pinpoint learning difficulties, which can be brought into light and helped overcome by means of modelling activities.

In traditional forms of mathematics teaching it is indeed possible to overlook or to disregard the fact that many of the students do not learn the key mathematical 
concepts at secondary level. Many students complete their secondary education with a rudimentary understanding of important concepts such as rational and real numbers, variable, equation, function, rate of change, derivatives and integrals. The problems become evident at tertiary level, where the students' mathematical conceptions are too fragile to form a basis for further education with mathematics.

From a systemic point of view, full integration of modelling and application in secondary mathematics teaching requires that the drawbacks of traditional forms of teaching when it comes to supporting the students' learning of key mathematical concepts are realized and that modelling is seen as a didactical means for overcoming such learning difficulties. Therefore, it is crucial that teachers can build upon an understanding of the theories pinpointing and explaining such learning difficulties. This is, however, quite demanding, since the relevant theories are difficult for teachers to relate to their practice. Accordingly, there is a challenge for research to find ways to support the interplay between theories on the learning of mathematical concepts and the development of teaching practice in modelling.

\subsection{Learning Mathematics Through Modelling in Practice}

Together with colleagues, and in collaboration with teachers during the years, I have been involved in developing and researching mathematical modelling as a means for supporting students' learning of mathematics from lower secondary level (Grade 7) to early university level. Typically, the projects or in-service courses have involved the teachers' planning, teaching, and evaluating modelling lessons or courses in their own practice. In general, the aim of these activities has been to support the integration of modelling in mathematics at lower secondary (Grades 7-9 in the Danish comprehensive school) and at upper secondary level (Grades 10-12 in the Danish gymnasium). In both systems modelling is included, but not really integrated, in the curriculum.

These experiences show that it is much easier for teachers to work with the aim of developing the students' modelling competence than to deliberately plan for modelling activities to support the students' learning of particular mathematical concepts. Typically, during courses, the teachers make use of the modelling cycle as a tool for planning a modelling course and as a tool for analysing the students' modelling work. However, it is more difficult for teachers to see and pinpoint for the students, the learning potentials in their modelling activities and to use such situations for challenging and developing the students' conceptual understanding. In particular, the teachers often find it difficult to draw on the students' different experiences and results from modelling activities in building a shared understanding in the class of the concepts or methods involved. It is difficult for the teachers to connect the students' modelling anchored understanding to the mathematical knowledge in the curriculum.

In developmental projects and in-service courses aiming at helping teachers integrate modelling as a means for supporting the students' learning of mathematics, we 
have been facing the challenge of how to make better use of theories on the learning of mathematical concepts (Blomhøj and Kjeldsen 2013b).

In particular, we have used theoretical ideas related to:

- the important role of representations for the learning of mathematical concepts (Steinbring 1987, 2005);

- concept images (Vinner and Dreyfus 1989);

- the process-object duality in concept formation (Sfard 1991); and

- the previously mentioned RME notion of the development from a model of some type of situation to a model for the understanding and learning of a mathematical concept (Gravemeijer and Doorman 1999).

All these theories have proven helpful for analysing the students' learning during their modelling work; for developing and improving modelling problems; and as a resource for supporting and challenging the students during their work with modelling projects in a first-year university course (Blomhøj and Kjeldsen 2010).

However, the theories are not easy to apply for teachers. Therefore, there is a need for tools, which can help teachers to see modelling activities as a didactical means for supporting the students' learning of key mathematical concepts. An example is the schema used in the following two examples for spanning the possible use of different forms of representations of process and object aspects of key mathematical concepts involved in a modelling process in a particular context.

The divide between process and object aspects is according to the model for formation of mathematical concepts developed by Sfard (1991). Of course the schema primarily makes sense in relation to concepts, which have clear process and object aspects, but even in such cases-as indicated in the two examples below-it is not a simple task to distinguish between representations of process and object aspects of mathematical concepts - the same representation (the same signs) can often be interpreted as referring to both process and object aspects of a concept.

For a given modelling activity, the schema can be filled out a priori in order to uncover the potentials for supporting the students' work with, and sense making of, representations of the mathematical concepts involved. Also, the schema can be used to structure and analyse evidence for the students' work with the different representations and their mutual connections in actual modelling activities.

In each cell it is possible to distinguish between the concrete model or modelling situation on the one hand, and a generalised model on the other hand; that is to emphasize the possible change of perspective from seeing the model at hand as a model of a particular situation to seeing it as an emerging generalised model for understanding the mathematical concept in focus (Gravemeijer and Doorman 1999). So far the schema has been used in courses and developmental projects in relation to: the function concept, linear functions, exponential functions, the derivative concept, and the integral concept. In the following two examples the schema is used to summarise the potentials for supporting the students' conceptual learning in relation to the modelling activities. 


\subsection{Modelling Dynamical Phenomena}

Two modelling situations at Grade 8 and 9 are presented. They can be seen as possible early elements in a longitudinal teaching and learning trajectory on the modelling of dynamical phenomena by means of compartment modelling, difference (and later differential) equations supported by the use of digital technology. The two examples include key mathematical concepts such as variable, function, rate of change and integrals. Of course, the concepts of rate of change and integrals are only present in the modelling activities as contextualized intuitive ideas. However, experiences from such modelling activities can provide the students with a foundation for learning calculus, and to develop gradually competence for modelling of dynamical phenomena during the upper secondary level. Blomh $\varnothing \mathrm{j}$ and Kjeldsen (2010) present and discuss a modelling project, which can be seen as a possible continuation of this trajectory at university level. This section illustrates how the previously discussed theories on the learning of mathematical concepts can be used to pinpoint potentials in modelling situations for supporting the students' conceptual learning.

\subsubsection{The Morning Shower}

A morning shower is a rich context for modelling a simple dynamical phenomenon, namely the use of water depending on the showering time. It can be used in lower secondary mathematics teaching from Grade 7 as a context for introducing linear functions. The idea originates from a project called Mathematical Mornings (Blomhøj and Skånstrøm 2006). In that project, the main idea was to challenge the students to use mathematics to describe and analyse some phenomena from their everyday morning life. The objectives were to: (1) motivate mathematical work, (2) establish stable cognitive roots for the students' conceptions of basic mathematical concepts, and (3) to provide the students with experiences of mathematics as a means for describing, analysing and understanding everyday life situations.

The task for the students was to produce an A3 poster of his or her mathematical morning based on observations and data. The students were expected to make a poster each of their own mathematical morning, but they were encouraged to help each other. This idea has been used many times in later projects and in-service courses and also by other educators. In many of these courses and projects the morning shower has proven to be a fruitful modelling task for supporting the students' learning of linear functions at lower secondary level. The students are (in our privileged culture) indeed very familiar with the real situation and they can quite easily see the connection between the duration of their shower and the amount of water used. From experience, many students can make the reasonable simplifying assumption that the flow of water can be assumed constant after the shower has begun. Also, quite often students notice themselves that there is some cold water in the pipeline, which has to run off before they enter the warm shower. Many students-especially girls-also notice that the 
duration of their showers depend on how much time they have and whether or not they wash their hair. A typical boy's remark is: "Coming after my sister I may not need to wait for the cold water to run off, but my shower will be short since she always uses almost all the warm water." In general, the students can easily activate their everyday experiences in relation to the real situation. This is of course a wonderful opportunity for the mathematics teacher to motivate the students' modelling work: "So you need a table, a graph or a formula, to give you the amount of water used for your shower depending on its duration". Based on such assumptions and reflections it makes sense for the students to measure the water flow in their own shower and the time they wait before entering the shower (or the amount of cold (not warm) water in the pipe, $W_{0}$ ). From a modelling perspective, it is a central point that meaningful measuring of the specific magnitudes has a conceptual model of the real situation as its prerequisite. In subsequent teaching the situation can be represented by a compartment diagram stressing that it is the amount of used water, $W(t)$, which we want to keep track of, while increasing by means of the constant water flow, $w f$ :

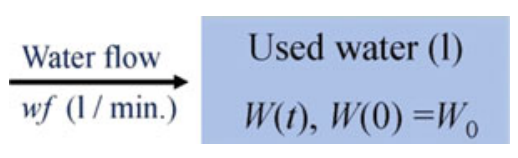

As illustrated in the photo in Fig. 3.1a it is not necessarily very easy in practice to measure the water flow in the shower. Students may need to repeat the measurement because they forget to measure the time needed to fill the bucket or because not all of the water goes into the bucket the first time. However, it is doable for most students, and with thoughtful planning of the course of lessons nearly all students can be expected to produce relevant data and to calculate the water flow for their own morning shower. From here they can produce tables, a graph and maybe even an algebraic representation of the amount of used water as a function of the duration of the shower. However, even if students can write an equation for a linear function modelling their shower, it is not at all necessary that they perceive this as a representation of a mathematical object.

Students can use a spreadsheet (Excel or GeoGebra) to produce a table by starting with the amount of cold water and adding the calculated water flow per minute for each consecutive minute and produce a graph by hand or by means of a spreadsheet. In this way the students work with representations of the process aspect of a linear function. Figure 3.1b shows a graph drawn using GeoGebra to represent the situation where a student has measured the water flow to be $6 \mathrm{~L}$ per minute and the amount of cold water as $3 \mathrm{~L}$. The points corresponding to time of showering and water used $(t, W)$ are calculated in a spreadsheet in GeoGebra, plotted and connected to form the stippled line in Fig. 3.1b. Based on concrete calculations of the amount of water used for showers of different duration, that is: $5,10,15 \mathrm{~min}$, the students can be challenged individually to set up an equation using $t$ (or $x$ ) as a variable for the time in minutes and $W$ for the water used in litres: $W=6 \mathrm{~L} / \mathrm{min} \cdot t+3 \mathrm{~L}$. Thereby, the students can gain support for developing their concept images of a graph of a function 
(a)

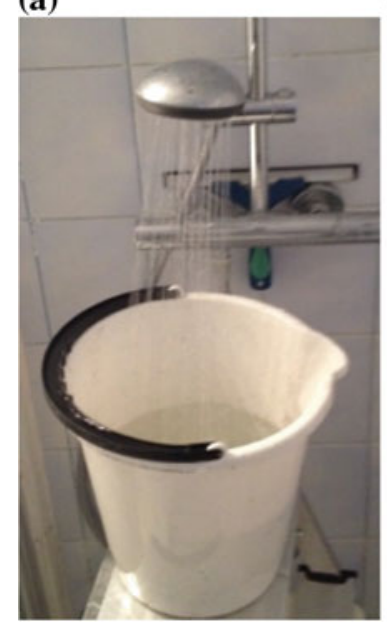

(b)

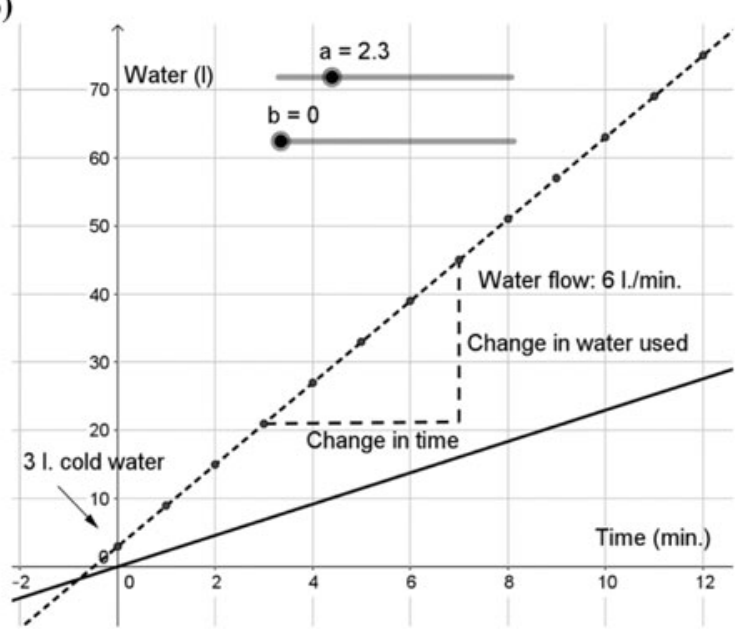

Fig. 3.1 a Measuring the flow in the shower and $\mathbf{b}$ representing the model graphically

as consisting of exactly the coordinate points created by the function relationship and therefore-in this case-fulfilling an equation defining the function.

The notion of students' concept images as developed by Vinner and Dreyfus (1989) pinpoints exactly the necessity for the students to work with all important aspects of a mathematical concept. It is easy to find students in Grade 10 or later, who cannot really make sense out of the fact that a given point belongs to the graph of a function in a given context. According to Vinner and Dreyfus, the explanation is simply that this relation is not part of their concept image of a function. In traditional mathematics teaching, it is possible to learn about functions and be able to draw graphs of functions and solve standard tasks, without understanding important connections between different representations of the function concept.

Individually, and in subsequent teaching for the whole class, the students can be challenged to write the general equation for a straight line shown in GeoGebra, $y=a x+b$, where the value for the parameters $a$ and $b$ can be changed by means of sliders as shown in Fig. 3.1b. By developing and experimenting with such an interactive sketch, the students can experience that the straight line through their points has a unique representation by the parameters $a$ and $b$. These can then be given their natural interpretations as the slope of the line (and in the real situation as the flow of water or the rate of change measured in litres/minute) and as the intersection with the $y$-axis (the cold water, the initial value of the state variable in litres).

Through such activities, the students can obtain support for taking the reification step in their formation of their concept of a (linear) function (Sfard 1991). They can experience a linear function as a representation of the process of calculating the amount of used water for a variation of the time of showering and see how this 


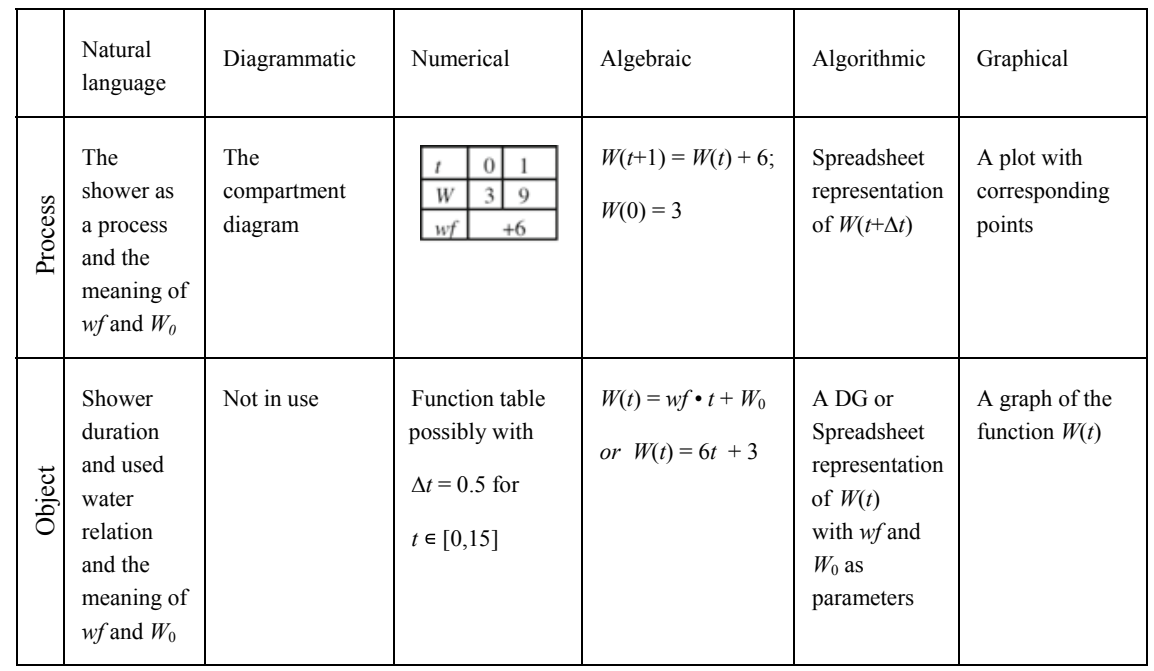

Fig. 3.2 Representations of a linear function in the Morning Shower

function can be seen as a mathematical object with certain qualities and different representations. As pinpointed by Sfard, this is a crucial step in the formation of mathematical concepts in general. Students' modelling work in situations that make sense for them has the potential to support this essential step in the concept formation process.

Through their modelling of the morning shower situation, students can construct a stable cognitive root for the concept of function as a process connecting to variables as well as a mathematical object, which can be represented in different forms: natural language, a diagram, a numerical table, an algebraic equation, an algorithmic representation, and a graphical representation. Thereby, the epistemological triangle (Steinbring 1987) for the concept of function can be spanned in different ways all referring to the morning shower situation with which the students have concrete experiences.

Moreover, through such activities the students may develop a model for understanding linear functions in general, that is, change the perspective from working with a model of some real situation to see the model at hand as a means for understanding a mathematical concept (Gravemeijer and Doorman 1999). In this case, it is even relevant to talk about the embodiment of the slope of a straight line and the rate of change, since the students after having modelled their shower, now have the power to change the slope of the line-within certain limitations of course-by turning the flow of water up or down during their showers. Such experiences provide a strong cognitive root for learning the concepts involved.

Figure 3.2 shows different forms of representations of a linear function that might come into play in the Morning Shower modelling activity. 
(a)

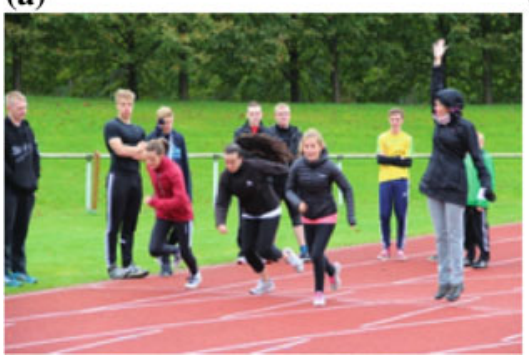

(b)

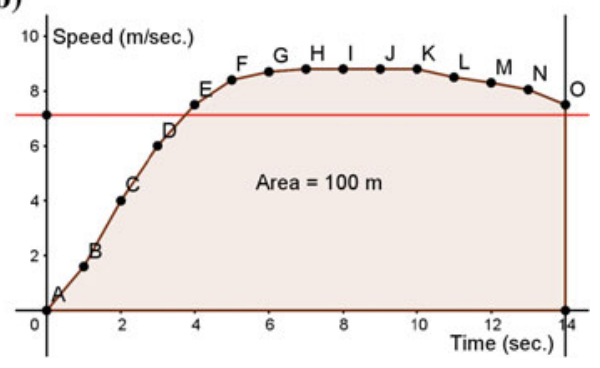

Fig. 3.3 a A $100 \mathrm{~m}$ sprint and b speed graph in GeoGebra for a sprint in $14 \mathrm{~s}$

\subsubsection{The $100 \mathrm{~m}$ Sprint}

The second example has its origin in a project where students in Grades 8-10 had the physical experience of running a $100 \mathrm{~m}$ sprint (see Fig. 3.3a). All should have had their individual time recorded. The aim of the activity is for each student to model his or her personal sprint in terms of describing mathematically how the speed and the distance changed during their sprint. The learning aim is to support the students' understanding of speed as the rate of change of the distance and establish a cognitive root for understanding the integral concept. The students' activity can be framed by the following connected tasks:

(1) Calculate your average speed in metres per second for your $100 \mathrm{~m}$ sprint. Make a coordinate system in GeoGebra in which you can depict your speed in $\mathrm{m} / \mathrm{sec}$ from the time you started to the end time of your sprint.

(2) Start by imaging that you had run with the same speed from the start to the end. Draw the speed graph for that situation. (Of course, you did not, since you stood still at the start of the race otherwise, there would have been a false start.)

(3) How can you calculate the distance that you have run from this graph? (Of course, you already know that it is $100 \mathrm{~m}$.)

(4) Assume that you have run with constant acceleration starting from still. Draw the graph for your speed from the start to your end time in this situation. With what speed would you have crossed the finish line in that situation? Is that a realistic possibility?

(5) Use the spreadsheet in GeoGebra to fill in for each second during your sprint, your best estimate for your speed at that exact moment of your sprint. Draw this speed graph in the same coordinate system. Adjust your speed estimates so as you reach the $100 \mathrm{~m}$ in the time from your real sprint.

From their experiences running the sprint and supported by their answers to the tasks (1)-(4), Grade 8-10 students can make reasonable estimates for their speed during their sprint in task (5). By making use of the dynamical interplay between the spreadsheet, the graph window in GeoGebra, and the calculation of the area under the speed graph, the students can adjust their estimated speed for each second during their sprint, so it fits with the $100 \mathrm{~m}$ in exactly their time. 
The graph for a case where the $100 \mathrm{~m}$ sprint is done in $14 \mathrm{~s}$ is shown as a GeoGebra figure in Fig. 3.3b. The figure also includes the graph for the constant speed equal to the average speed of $7.14 \mathrm{~m} / \mathrm{s}$ as the horizontal line. The points $\mathrm{A}, \mathrm{B}, \ldots, \mathrm{O}$ are taken from the spreadsheet in GeoGebra and the area (the distance) is calculated dynamically by means of the tool 'Area of polygon'. If a point is changed, say point $\mathrm{E}(4,7.5)$ to $(4,6.5)$, the area will change from 100 to $99 \mathrm{~m}$ because $1 \mathrm{~m} / \mathrm{s}$ for $1 \mathrm{~s}$ is missing in order to reach the $100 \mathrm{~m}$ in $14 \mathrm{~s}$.

These features in GeoGebra enable the students to estimate realistic speed graphs for their sprint and to experience the direct relationship between the speed in each second and the distance (the area) covered.

The situation can also be represented by means of a compartment model:

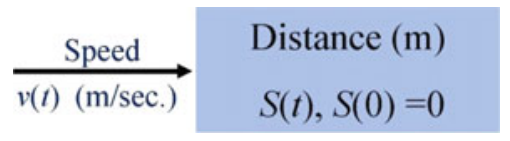

The compartment model of the $100 \mathrm{~m}$ sprint can be seen as a generalization of the model for the shower, since in this case the rate of change is a non-constant function. The speed function, $v(t)$, cannot be given by a simple algebraic expression. However, from the students' experiences with the real situation it is conceptually clear for most students that their $100 \mathrm{~m}$ sprint can be modelled by a speed function represented by a graph. Hence, the modelling of the $100 \mathrm{~m}$ sprint can contribute to the extension of the students' concept image of a function to include relationships, which is not defined by an algebraic expression. In addition, this activity has the potential for developing into a "model for" the students' understanding of how the distance is determined by the speed and how it can be calculated by means of summing up (integrating) the speed.

The compartment approach to the modelling of dynamical phenomena can be continued in upper secondary level and at university level supporting the students' modelling competence as well as their mathematical understanding. The compartment representation provides — at least for some students — a foundation for understanding the fundamental theorem of calculus:

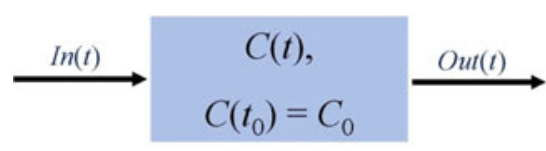

$$
\begin{aligned}
& C^{\prime}(t)=\operatorname{In}(t)-\operatorname{Out}(t) ; C_{0}=C\left(t_{0}\right) \\
& C\left(t_{1}\right)=C_{0}+\int_{t_{0}}^{t_{1}} \operatorname{In}(t)-O u t(t) d t
\end{aligned}
$$

The net rate of change for a compartment is the sum of inflows minus the sum of outflows. The level of a compartment at time $t$ is the value at previous $t_{0}$ plus the integral of the net rate of change from $t_{0}$ to $t$. Together with experiences from modelling dynamical phenomena as in the two examples of the compartment formulation constitutes an intuitive explanation of the fundamental theorem of calculus. Hereby, it is also indicated how a longitudinal learning trajectory within the modelling of dynamical phenomena by means of compartments and difference equation can help 


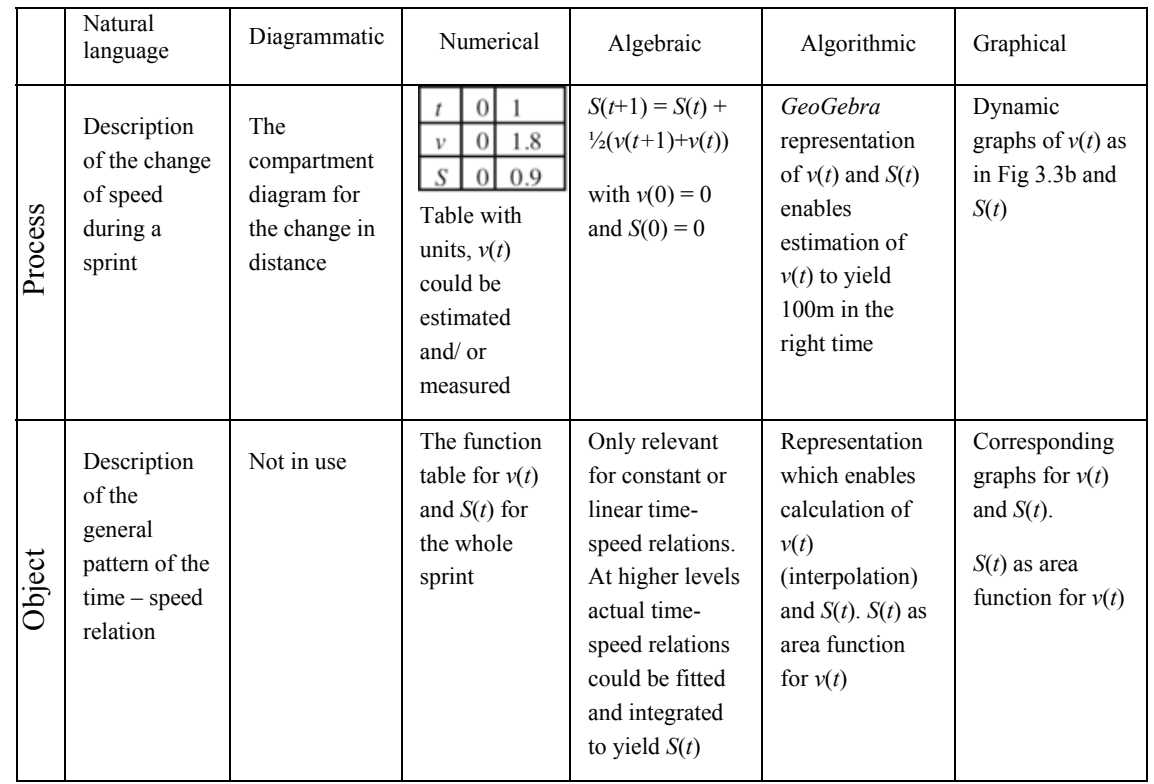

Fig. 3.4 Representations of the time-speed-distance relationships in The $100 \mathrm{~m}$ Sprint

overcome learning difficulties connected to key mathematical concepts (Blomhøj and Kjeldsen 2010, 2013a).

The possible representations of the process and object aspects of the relationships between time, speed and distance, which can come into play in this modelling activity are summed up in the schema in Fig. 3.4.

\subsection{Conclusion}

Mathematics education research has a lot to offer for helping the integration of mathematical modelling in secondary mathematics teaching. In general, the theory-practice relation stands differently with respect to the educational aim of developing the students' modelling competencies and the aim of supporting the students' learning of mathematics through modelling activities respectively (Blomhøj and Ärlebäck 2018).

With regard to the objective of developing the students' modelling competencies research is already quite well aligned with the development of practice. Projects and courses in classrooms are already to some degree based on theoretical notions and ideas developed in research. Of course, there are still challenges for research, such as conceptualising - also for assessing — the students' progress in modelling competency. 
In order for modelling and applications to be fully integrated in secondary mathematics teaching, modelling should also be seen and understood as a didactical means for supporting the students' learning of mathematics. Here also, theories are available in the form of the frameworks mentioned and in the form of theories on difficulties related to the learning of mathematical concepts. These theories can serve as a basis for the justification of modelling as an integrated element in secondary mathematics teaching in curricula reforms. The theories also provide a basis for designing teaching, where modelling is used as the didactical means for supporting the students' conceptual learning. However, in order to be helpful for teachers the theories need to be concretized and re-contextualised in developmental projects or in-service education. The schema of representations shown here is one example of how research can develop tools, which can help researchers and teachers to connect theories on the learning of mathematical concepts to concrete modelling activities. Designing and investigating longitudinal learning trajectories for the students' learning of important mathematics through modelling activities as illustrated above could be another possible research approach for furthering integration of modelling in secondary mathematics teaching.

Of course, even though research may provide a necessary basis for the integration of modelling in curricula and in teaching practices at secondary level, it is not in any way sufficient for ensuring the integration in practice. As pointed out by Blum (2015), systemic approaches are needed in order to really support the integration of modelling in the practice of secondary mathematics teaching. Here, a main challenge for research is to develop and test methodologies for collaboration between researchers and teachers in various institutional contexts. Araújo (2019) develops and discusses a framework for a dialectical relationship between pedagogical practice and research in mathematical modelling, which may serve as a basis for developing such methodologies.

\section{References}

Araújo, J. (2019). Toward a framework for a dialectical relationship between pedagogical practice and research. In G. A. Stillman \& J. P. Brown (Eds.), Lines of inquiry in mathematical modelling research in education (pp. 21-36). Cham: Springer.

Blomhøj, M., \& Ärlebäck, J. B. (2018). Theory-practice relations in research on applications and modelling. In T. Dreyfus, M. Artigue, D. Potari, S. Prediger, \& K. Ruthven (Eds.), Developing research in mathematics education-Twenty years of communication, cooperation and collaboration in Europe. London: Routledge.

Blomhøj, M., \& Højgaard, T. (2007). What's all the fuss about competences? Experiences with using a competence perspective on mathematics education to develop the teaching of mathematical modelling. In W. Blum, P. L. Galbraith, H.-W. Henn, \& M. Niss (Eds.), Modelling and applications in mathematics education. The 14th ICMI study (pp. 45-56). New York: Springer.

Blomhøj, M., \& Kjeldsen, T. H. (2010). Learning mathematics through modelling: The case of the integral concept. In B. Sriraman, C. Bergsten, S. Goodchild, G. Pálsdóttir, B. Dahl, \& L. Haapasalo (Eds.), The first sourcebook on Nordic research in mathematics education (pp. 569-582). Charlotte, NC: Information Age Publishing. 
Blomhøj, M., \& Kjeldsen, T. H. (2013a). Students' mathematical learning in modelling activities. In G. A. Stillman, G. Kaiser, W. Blum, \& J. P. Brown (Eds.), Teaching mathematical modelling: Connecting to research and practice (pp. 141-152). Dordrecht: Springer.

Blomhøj, M., \& Kjeldsen, T. H. (2013b). The use of theory in teachers' modelling projects-Experiences from an in-service course. In B. Ubuz, C. Haser, \& M.A. Mariotti (Eds.), Proceedings of CERME 8. Ankara: Middle East Technical University and ERME.

Blomhøj, M., \& Skånstrøm, M. (2006). Matematik Morgener - matematisk modellering i praksis. In I. O. Skovsmose \& M. Blomhøj (Eds.), Kunne det tankes? - om matematiklaring (pp. 7-23). København: Malling Beck.

Blum, W. (2015). Quality teaching of mathematical modelling: What do we know, what can we do? In S. J. Cho (Ed.), The Proceedings of the 12th International Congress on Mathematical Education-Intellectual and Attitudinal Challenges (pp. 73-96). New York: Springer.

Borromeo Ferri, R. (2006). Theoretical and empirical differentiations of phases in the modelling process. ZDM Mathematics Education, 38(2), 86-95.

Chevallard, Y. (2011). La notion d'ingénierie didactique, un concept à refonder. Questionnement et éléments de réponse à partir de la TAD. In C. Margolinas, M. Abboud-Blanchard, L. BuenoRavel, N. Douek, A. Fluckiger, P. Gibel, F. Vandebrouck, \& F. Wozniak (Eds.), En amont et en aval des ingénieries didactiques (pp. 81-108). Grenoble: La Pensée Sauvage.

Doerr, H., \& Lesh, R. (2011). Models and modelling: Perspectives on teaching and learning of mathematics in the twenty-first century. In G. Kaiser, W. Blum, R. Borromeo Ferri, \& G. Stillman (Eds.), Trends in teaching and learning of mathematical modelling (pp. 247-268). Dordrecht: Springer.

Freudenthal, H. (1983). Didactical phenomenology of mathematical structures. Dordrecht: Reidel. Gravemeijer, K., \& Doorman, M. (1999). Context problems in realistic mathematics education: A calculus course as an example. Educational Studies in Mathematics, 39, 111-129.

Kaiser, G., \& Brand, S. (2015). Modelling competencies: Past development and further perspectives. In G. Stillman, W. Blum, \& M. S. Biembengut (Eds.), Mathematical modelling in education research and practice (pp. 129-149). Cham: Springer.

Kaiser, G., \& Sriraman, B. (2006). A global survey of international perspectives on modelling in mathematics education. ZDM Mathematics Education, 38(3), 302-310.

Lesh, R. A., \& Doerr, H. M. (Eds.). (2003). Beyond constructivism: Models and modeling perspectives on mathematics problem solving, learning, and teaching. Mahwah, NJ: Erlbaum.

Maaß, K. (2006). What are modelling competencies? ZDM Mathematics Education, 38(2), 113-142.

Niss, M., Blum, W., \& Galbraith, P. (2007). Introduction. In W. Blum, P. Galbraith, H.-W. Henn, \& M. Niss (Eds.), Modelling and applications in mathematics education. The 14th ICMI study (pp. 3-32). New York: Springer.

Niss, M., \& Højgaard, T. (2011). Competencies and mathematical learning: Ideas and inspiration for the development of mathematics teaching and learning in Denmark. IMFUFA-tekst nr. 485, Roskilde University.

Sfard, A. (1991). On the dual nature of mathematical conceptions: Reflections of processes and objects as different sides of the same coin. Educational Studies in Mathematics, 22, 1-36.

Steinbring, H. (1987). Routine and meaning in the mathematics classroom. For the Learning of Mathematics, 9, 24-33.

Steinbring, H. (2005). The construction of new mathematical knowledge in classroom interaction: An epistemological perspective. New York: Springer Science \& Business Media.

vom Hofe, R., Kleine, M., Blum, W., \& Pekrun, R. (2005). On the role of "Grundvorstellungen" for the development of mathematical literacy-First results of the longitudinal study PALMA. Mediterranean Journal for Research in Mathematics Education, 4, 67-84.

Vinner, S., \& Dreyfus, T. (1989). Images and definitions of the concept of function. Journal for Research in Mathematics Education, 20, 356-366. 
Open Access This chapter is licensed under the terms of the Creative Commons Attribution 4.0 International License (http://creativecommons.org/licenses/by/4.0/), which permits use, sharing, adaptation, distribution and reproduction in any medium or format, as long as you give appropriate credit to the original author(s) and the source, provide a link to the Creative Commons license and indicate if changes were made.

The images or other third party material in this chapter are included in the chapter's Creative Commons license, unless indicated otherwise in a credit line to the material. If material is not included in the chapter's Creative Commons license and your intended use is not permitted by statutory regulation or exceeds the permitted use, you will need to obtain permission directly from the copyright holder.

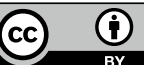

